\title{
A INTERCOMPREENSÃO NO ENSINO DO ESPANHOL: VIVÊNCIAS EM UM CURSO ONLINE DO FIVU
}

\author{
La Intercomprensión en la Enseñanza del Español: Vivencias en un \\ Curso en Línea del FIVU
}

\author{
Gabriela Cardoso HERRERA \\ Universidade Federal do Paraná \\ herrera@ufpr.br \\ https://orcid.org/0000-0002-3424-8501 \\ Fernanda Silva VELOSO \\ Universidade Federal do Paraná \\ fernandaveloso@ufpr.br \\ https://orcid.org/0000-0002-5263-6479
}

\begin{abstract}
RESUMO: O objetivo deste texto é apresentar algumas atividades, baseadas nos principais postulados da Intercompreensão, realizadas em sala de aula virtual — plataforma de videoconferência Microsoft Teams. No total, oito concluintes de licenciatura em Letras Espanhol ministraram, na condição de estagiários e professores em formação, 60 horas-aula para alunos de pós-graduação matriculados em um curso de Espanhol Básico do projeto Formação em Idiomas para Vida Universitária (FIVU). Tendo em vista o período de pandemia, o referido curso, ofertado antes presencialmente a alunos em sua maioria da graduação, ganhou um novo formato e foi realizado de maneira online. A fim de aproximar o nosso público-alvo da língua espanhola, optamos por iniciar a primeira, das muitas unidades elaboradas, com atividades de intercompreensão, que, atualmente, é reconhecido como método para o ensino integrado de línguas, principalmente românicas. Embasaram as análises de nossas atividades, bem como da sua aplicação, as teorias sobre tal método, principalmente aquelas discutidas por Escudé e Olmo (2019). Segundo os autores, quando dois interlocutores se encontram, cada um falando - ou escrevendo - sua própria língua e se esforçando para entender a língua do outro, ocorre a intercompreensão. PALAVRAS-CHAVE: intercompreensão, plurilinguismo, espanhol para fins acadêmicos.
\end{abstract}

RESUMEN: El objetivo de este texto es presentar algunas actividades, basadas en los principales postulados de la Intercomprensión, realiza-

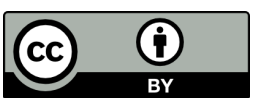


das, en salón de clase virtual — plataforma de videoconferencia Microsoft Teams. En total, ocho estudiantes concluyentes de la Licenciatura en Letras Español impartieron, en calidad de practicantes y profesores en formación, 60 horas/clase para alumnos de posgrado matriculados en un curso de Español Básico del Formação em Idiomas para Vida Universitária (FIVU). Teniendo en cuenta el periodo de pandemia, dicho curso, ofertado antes presencialmente, en su mayoría, a alumnos no graduados, recibió un nuevo formato y fue realizado en línea. A fin de acercar nuestro público objetivo de la lengua española, optamos por iniciar la primera de las muchas unidades elaboradas con actividades de intercomprensión, que, actualmente, es reconocido como un método para la enseñanza integrada de lenguas, principalmente romances. Basaron los análisis de nuestras actividades, así como de su aplicación, las teorías sobre tal método, sobre todo las discutidas por Escudé y Olmo (2019). Según los autores, cuando dos interlocutores se encuentran, cada quien hablando - o escribiendo - en su propia lengua y esforzándose para entender la lengua del otro, ocurre la intercomprensión. PALABRAS CLAVE: intercomprensión, plurilingüismo, español con fines académicos.

\section{INTRODUÇÃO}

Primeiro semestre de 2020: pandemia do Covid-19, quarentena em casa, aulas presenciais suspensas sem previsão de retorno, enfim, todos vivendo num momento bastante atípico. Nesse cenário, foi proposto aos alunos de Prática de Docência em Língua Estrangeira Moderna II (Neolatinas) que continuassem as atividades da disciplina de maneira remota. Para isso, foi ofertado um curso de espanhol de 60 horas-aula, vinculado ao projeto Formação em Idiomas para Vida Universitária (FIVU), para estudantes da UFPR do Programa de Pós-Graduação em Educação (PPGE).

O curso, que ocorreu nos meses de junho e julho de 2020, contou com a participação de oito alunos de Prática II, que elaboraram unidades temáticas e ministraram aulas de espanhol básico - utilizando a plataforma de videoconferência Microsoft Teams - para cerca de 30 alunos do PPGE, divididos em duas turmas. No total, foram ministradas 30 horas-aula de língua espanhola e oito horas de cultura hispana para ambas as turmas.

A fim de aproximar o público-alvo da língua espanhola, foi optado por iniciar o curso com uma atividade de intercompreensão, que, atualmente, é reconhecida como método para o ensino integrado de línguas, principalmente românicas, como é o caso do espanhol e do português, respectivamente língua-alvo e língua de origem do curso. 
Em vários momentos do curso as atividades de intercompreensão se fizeram presentes, mas, neste texto, optou-se por discutir apenas as que constam na primeira unidade didática utilizada para o ensino do espanhol. É necessário apontar que todo o material didático utilizado no curso foi elaborado pelos praticantes a partir de textos autênticos.

Para pensar sobre a intercompreensão e elaborar essas atividades, foi usado como referência o livro Intercompreensão: a chave para as línguas, de Pierre Escudé e Francisco Calvo del Olmo (2019), além da tese A intercompreensão no ensino de línguas estrangeiras: reflexões sobre a prática em Leitura plurilíngue na escola, curso oferecido em uma escola estadual de ensino médio em Vitória (ES), de Igor Castilho Porsette (2019), e da dissertação Práticas de Intercompreensão entre línguas românicas: desenvolvimento da competência de leitura plurilíngue de estudantes de ensino médio de uma escola técnica (ETEC) de São Paulo, de Cristina Helena Carola (2015).

Antes de passar para a análise das atividades, é importante apresentar o que se entende por intercompreensão, uma prática que embora seja recente no âmbito de estudos da linguística aplicada, existe há séculos de modo natural e instintivo, sempre que "dois interlocutores se encontram, cada um falando - ou escrevendo - sua própria língua e se esforçando para entender a língua do outro" (ESCUDÉ; OLMO, 2019, p. 11).

\section{DEFININDO A INTERCOMPREENSÃO}

Apenas na década de 1990 o conceito da intercompreensão como recurso didático começou a ser desenvolvido, porém esse termo aparece pela primeira vez em 1913, cunhado pelo linguista francês Jules Ronjat. Conceituar a intercompreensão não tem sido uma tarefa fácil, já que nos discursos dos pesquisadores são usadas diversas referências conceituais, corroborando sua "inerente polissemia", nas palavras de Mônica Palmerini e Serena Faone (2014, p. 143-144):

A inerente polissemia do termo não faz senão espalhar [...] um estágio de constante evolução dos limites do campo da pesquisa, no qual o conceito da intercompreensão encontra-se a reagir às várias declinações de uso com as quais circula na comunidade científica, que o desenvolve, o completa, o adapta, o modifica, associando-o a diversas referências [...]. Por outro lado, essa deformação contínua da noção de intercompreensão é sintomática do caráter inerentemente transversal da categoria conceitual que se encontra no ponto de intersecção entre o estudo da comunicação através de sistemas de signos (semiótica), o estudo das línguas verbais (a linguística), o estudo da variação linguística (a tipologia linguística, a linguística diacrônica, 
a sociolinguística, a linguística espacial), a didática das línguas e a política linguística.

Essa pluralidade de possibilidades que a intercompreensão apresenta pode gerar alguma confusão, mas se trata, na verdade, de uma experiência vivenciada por todos quando, ao ler um texto numa língua românica diferente do português, ou ao tentar se comunicar com um falante dessa língua, conseguem se "aproximar dessa língua estrangeira - em teoria desconhecida —, compreender as informações principais mesmo com dificuldades - e inclusive interagir [usando a própria língua portuguesa]" (ESCUDÉ; OLMO, 2019, p. 11). Essa modalidade de comunicação ancestral possui vantagens

[...] tanto em termos de eficiência, pois cada interlocutor usa uma língua que conhece bem, quanto em termos de igualdade, já que ninguém impõe sua língua ao outro nem se vê constrangido a arranhar uma língua com insegurança” (ESCUDÉ; OLMO, 2019, p. 12).

Ao se colocar em contato dois falantes de línguas românicas diferentes, fica evidente a busca por pontos de contato entre elas, semelhanças que permitam que a comunicação se realize, apesar das diferenças. Para tratar dessas semelhanças e diferenças, Escudé e Olmo utilizam formulações teóricas do linguista suíço Ferdinand de Saussure (1857-1913), presentes na obra Curso de linguística geral (1916) — publicada após a sua morte por alguns discípulos. Nela, que tem como objetivo central estabelecer uma metodologia para estudar o funcionamento da linguagem enquanto capacidade humana, Saussure afirma que, numa comunicação, qualquer distância entre emissor (autor) e receptor (leitor), seja ela espacial ou temporal, sempre gera uma tensão, já que agem simultaneamente sobre ela duas forças: o "espírito de campanário" (que Escudé e Olmo chamam de "paroquialismo") e a "força do intercurso":

Os termos saussurianos são bastante explícitos: o paroquialismo vai em direção à valorização de tudo quanto é local e à caracterização de grupos pequenos cujos membros criam fortes laços emocionais, formando socioletos e variedades locais, léxicos e gírias específicos, formas marcadas pela idade ou por referentes culturais precisos — tudo isso tende à refração, ao distanciamento. [...]. Já a força do intercurso reúne todos os fenômenos que promovem intercâmbios entre comunidades mais ou menos próximas e se posiciona no rumo da fusão, da identificação mútua. (ESCUDÉ; OLMO, 2019, p. 16-17). 
Percebe-se que Saussure não trata de uma comunicação feita entre duas pessoas que utilizam diferentes idiomas, mas os conceitos de paroquialismo - relacionado à identidade e ao orgulho de pertencer a um grupo - e de força de intercurso destacando não apenas as diferenças, mas também as possíveis trocas — cabem perfeitamente na prática da intercompreensão, a qual "permite interagir com grupos mais ou menos afastados, seguindo a força do intercurso, sem renunciar à própria voz em suas particularidades, ou seja, ao paroquialismo" (ESCUDÉ; OLMO, 2019, p. 17).

A partir dessa afirmação, é possível considerar que, no plano pedagógico, uma "metodologia baseada na intercompreensão, consiste em aprender e tratar simultaneamente esses dois aspectos: reconhecer os fenômenos lexicais e gramaticais comuns e atentar para a singularidade própria de cada língua" (ESCUDÉ; OLMO, 2019, p. 62). Portanto a intercompreensão enquanto abordagem didática para o ensino de línguas românicas, assim como outras abordagens que a antecederam, utiliza a comparação entre as línguas para "analisar os pontos em comum e as particularidades de cada idioma no interior da família”. (ESCUDÉ; OLMO, 2019, p. 61).

Apesar de considerar tanto as diferenças como as semelhanças entre duas (ou mais) línguas, é importante ressaltar que a intercompreensão, ao contrário de outras metodologias baseadas em comparações, se apoia principalmente nas semelhanças linguísticas, e não nas diferenças. Evidenciar as semelhanças entre as línguas românicas as aproxima ainda mais, fazendo com que as línguas-alvo possam ser entendidas como variações de origem dos alunos, "já que cada uma delas realiza de forma diferente as características da família linguística” a que pertencem. (ESCUDÉ; OLMO, 2019, p. 61).

Vale ressaltar que, devido a uma visão normativa que valoriza apenas o uso da língua estrangeira com uma exatidão rigorosa e condena o uso da língua materna, caso do método Audiolingual (ANTONHY, 1963; LEFFA, 1988) — presente em algumas franquias de ensino de línguas, ainda que com uma nova "roupagem" fazer comparações e aproximações entre a língua-alvo e a língua de origem, no âmbito acadêmico, não são considerados recursos legítimos na maioria dos casos, já que as línguas ainda são vistas como realidades estanques.

É importante destacar que a intercompreensão é apenas uma das dimensões que compõem as abordagens plurais. Tais abordagens ganham forma no início dos anos 2000, quando é publicado o Guia para a Elaboração de Políticas Linguísticas Educativas na Europa (2003, 2007). Nesse documento, um dos conceitos que permitem o entendimento da questão linguística no continente é justamente o plurilinguismo (PORSETTE, 2019). 
O plurilinguismo, segundo Beacco (2005, p. 19), é visto como a competência dos falantes capazes de empregar mais de uma língua. A competência plurilíngue, portanto, é "a concretização da capacidade de linguagem, que todo ser humano dispõe geneticamente e que pode ser investida sucessivamente em várias línguas"1 (tradução nossa).

O repertório linguístico de cada falante pode ser, ainda de acordo com o autor, “constituído por diferentes línguas às quais ele se apropriou de diferentes maneiras e nas quais adquiriu habilidades linguísticas diferentes (conversação, leitura, audição etc.), em níveis de proficiência diferentes"2 (BEACCO, 2005, p. 20, tradução nossa). Assim, não é preciso que todas as habilidades linguísticas da língua-alvo estejam desenvolvidas igualmente para que se adote, em sala de aula, uma abordagem plural.

Com o objetivo de descrever e sistematizar um conjunto de competências e recursos para o desenvolvimento de abordagens plurais para o ensino de línguas, elaborou-se e publicou-se, em 2007, o CARAP 10 - Un Marco de Referencia para los Enfoques Plurales de las Lenguas y de las Culturas (2013) ${ }^{3}$, documento que propõe novas abordagens para o ensino e aprendizagem de línguas, dentre elas a da intercompreensão.

$\mathrm{O}$ que todas essas abordagens têm em comum é a exposição do aluno a mais de uma língua simultaneamente e se opõem, portanto, àquelas "que poderiam ser denominadas 'singulares', cujo enfoque didático é centrado exclusivamente numa só língua ou numa cultura determinada, isoladamente, sem nenhuma referência a outras línguas ou culturas."”4 (CANDELIER, 2013, p. 6, tradução nossa).

\section{A ABORDAGEM DE INTERCOMPREENSÃO NA PRÁTICA}

Para o curso de Espanhol Básico do FIVU, que contextualizamos na introdução deste relato, as aproximações foram bem-vindas não apenas no início, com as atividades de intercompreensão que serão analisadas a seguir, como também durante todo o

\footnotetext{
${ }^{1}$ No original: "concrétisation de la capacité de langage, dont tout être humain dispose génétiquement et qui peut s'investir successivement dans plusieur langues".

${ }^{2}$ No original: "constitué par des langues différentes qu'il s'est appropriées selon des modalités diverses et pour lesquelles il a acquis des compétences différentes (conversation, lecture, écoute...), à des niveaux de maîtrise eux-mêmes différents".

${ }^{3}$ CARAP, sigla em francês para Cadre de Référence pour les approches plurielles des Langues et des Cultures, publicado em 2007.

${ }^{4}$ No original: "que se podrían denominar 'singulares' cuyo planteamiento didáctico se centra exclusivamente en una sola lengua o una cultura determinada, aisladamente sin ninguna referencia a otras lenguas o culturas".
}

Revista X, v. 16, n. 4, p. 1062-1078, 2021. 
processo. Inclusive, o "portunhol" 5 foi valorizado todo o tempo, como "lugar de passagem de trânsito de significados e formas, da transição entre a língua de origem e a língua-alvo, de mapeamento da distância entre uma e outra para construir a compreensão do que é comum e diferente" (ESCUDÉ; OLMO, 2019, p. 75).

As atividades de intercompreensão, que constam em anexo, abriram o curso e também a unidade temática, intitulada "Primeros Contactos", na primeira semana de aula. Seu título já sugere que foi elaborada considerando que falantes de português como língua materna - como era o caso de todos os alunos matriculados — teriam seu primeiro encontro formal com a língua espanhola. No entanto, a intenção foi elaborar um material que reforçasse que os estudantes, mesmo com pouco conhecimento prévio da língua estrangeira que começariam a aprender, não estavam partindo do zero, porque os dois idiomas são parentes próximos, línguas românicas que, junto do galego e do asturiano, formam o grupo ibero-românico. Para isso, foi escolhida a abordagem da intercompreensão, por suas características comparativas e, sobretudo, por valorizar as semelhanças entre as línguas. Assim, os alunos, falantes proficientes do português, seriam estimulados a, desde o início, estabelecer pontes entre o conhecido e o novo, "levantar passarelas, provocar o reflexo do previsível; procurar - além das irregularidades, diferenças e codificações específicas - fenômenos de regularidade e sentido" (ESCUDÉ; OLMO, 2019, p. 61).

O material autêntico escolhido para iniciar o curso, a partir do qual foram elaboradas as atividades, foi a introdução do texto "Abordaje comunicativo en la enseñanza de ELE", de Beatriz Cea, extraído do site da autora ${ }^{6}$, no qual ela oferece aulas online de espanhol. Ela, que é uruguaia, mas vive no Brasil, apresenta esse texto para esclarecer o que é a abordagem comunicativa, método que ela utiliza em suas aulas. Esse texto foi escolhido porque o curso ofertado usaria a mesma abordagem, e foi considerado muito relevante que os alunos da PPGE, tão intimamente ligados à área da Educação, mas não necessariamente do ensino de LE, ficassem cientes disso desde o início. Inclusive, o texto completo foi enviado para os alunos lerem antes mesmo do primeiro encontro.

No entanto, algumas partes desse texto, que não estão na sua introdução e, portanto, não aparecem na atividade de intercompreensão proposta na unidade, tiveram que ser adaptadas, pois traziam afirmações que consideramos extremistas e obsoletas.

\footnotetext{
${ }^{5}$ Não ignoramos a existência de diversas perspectivas sobre o "portunhol", que ora é nomeado interlíngua, ora dialeto e ora língua. No entanto, não é nosso objetivo promover tal discussão neste texto.

${ }^{6}$ Disponível em: https://didacticadeele.com/blog/didactica-y-metodologia/abordaje-comunicativoensenanza-ele/. Acesso em: 20 maio 2020.
} 
Uma delas diz respeito ao uso exclusivo da língua estrangeira durante um curso que a ensina. Pensamos que é, sim, importante utilizar a língua-alvo na maior parte do tempo (ou, ao menos, a interlíngua ou língua de processo), mas que interferências pontuais usando a língua materna não são tão maléficas quanto se considerava quando a abordagem comunicativa passou a ser a mais difundida e valorizada. A outra alteração se refere ao fato de ser proibida a correção dos erros dos alunos, já que eles mesmos deveriam se autocorrigir. Interromper várias vezes a fala de um aluno para corrigi-lo pode sim atrapalhar o seu desenvolvimento na língua estrangeira, já que, provavelmente, ele terá a sensação de não conseguir produzir nada de maneira correta e pode, por acanhamento, deixar de tentar e acabar perdendo a motivação de aprender, uma peça-chave no ensino de qualquer idioma. Porém, acreditamos que o professor deve sim corrigir o aluno, para que erros não sejam fossilizados, mas, obviamente, com parcimônia e bom senso, esperando o momento adequado para fazer a correção.

É importante frisar que o fato de o curso ser pautado num viés comunicativo e sociointeracionista não impede o uso da intercompreensão, já que ela, "enquanto abordagem pedagógica, não pretende substituir outras metodologias precedentes; ela assume uma posição pragmática no que tange ao nosso modo de ser e de interagir nas línguas" (ESCUDÉ; OLMO, 2019, p. 13).

A escolha de um texto escrito, e não de outro tipo de material autêntico, ocorreu porque a língua escrita "contribui para produzir certezas e reforçar a autoconfiança dos estudantes" por ser "durável”, apesar das mudanças de contextos (ESCUDÉ; OLMO, 2019 , p. 67), e por permitir que o aprendiz leia e releia o texto, ou partes dele, quantas vezes forem necessárias para apreender seu sentido global, mesmo que não seja possível inferir o significado de todas as palavras.

Foram elaboradas seis atividades a partir do texto-base citado A primeira atividade propõe uma avaliação pessoal sobre o grau de dificuldade da leitura; a segunda, pede uma informação específica dada no texto; a terceira, de interpretação, foi construída na modalidade V ou F; a quarta, por fim, traz uma palavra em espanhol, opaca para falantes de português, para ser combinada com sinônimos mais transparentes, que ajudam a, pelo contexto, inferir o significado da palavra desconhecida em questão; a quinta estimula os alunos a voltarem ao texto para encontrarem os equivalentes em espanhol para palavras em português, e a sexta, única com o enunciado em espanhol, promove uma reflexão sobre os dois idiomas a partir das palavras encontradas na atividade anterior e na experiência de leitura silenciosa do texto como um todo. 
Nota-se que a intenção das atividades é ir aproximando os alunos, tanto da língua espanhola, quanto gradativamente da prática da intercompreensão, já que primeiro estimulam a leitura vertical do texto - mais usual também em outros tipos de abordagens didáticas, pois trata do conteúdo - e depois da leitura horizontal - característica mais específica da abordagem em intercompreensão, já que examina as formas a partir de comparações entre os idiomas.

O objetivo da primeira atividade — “(a) De 0 a 100\%, quanto você considera que entendeu do texto?" - é que esse estudante, que (supostamente) acaba de entrar num universo novo, perceba que ele não é tão desconhecido assim, pois pode ser compreendido "apenas" com as ferramentas que já traz do seu próprio universo e, com isso, sinta-se desde o início mais confiante.

Já as atividades seguintes, (b), (c) e (d), são mais tradicionais no ensino de línguas estrangeiras porque trabalham com interpretação de texto. Portanto é indispensável uma análise mais detalhada apenas dos dois últimos exercícios.

As atividades (e) e (f), totalmente relacionadas entre si, e reproduzidas a seguir, apresentam uma lista de palavras em português, cujas traduções estão no texto, para que os alunos, a partir delas, criem hipóteses sobre a relação dos dois idiomas — ou seja, suas semelhanças, a força do intercurso saussuriana - e as características específicas do espanhol - as particularidades que o tornam único, o paroquialismo, para assim, "sistematizar as correspondências entre as línguas e trabalhar a variação, [...] elementos centrais para uma aprendizagem em intercompreensão”. (ESCUDÉ; OLMO, 2019, p. 59). 
Figura 1: Atividades (E) e (F).

e) Procure no texto as seguintes palavras (em espanhol):

\begin{tabular}{|l|l|}
\hline INSTITUTOS & \\
\hline ESPECÍFICOS & \\
\hline METODOLOGIA & \\
\hline TERMINOLOGIA & \\
\hline PRINCÍPIOS & \\
\hline PRATICAMENTE & \\
\hline PROMETEM & \\
\hline UTILIZAM & \\
\hline PUBLICIDADE & \\
\hline REALIDADE & \\
\hline
\end{tabular}

\begin{tabular}{|l|l|}
\hline COMUNICAÇÃO & \\
\hline FORMULAÇÃO & \\
\hline ABORDAGEM & \\
\hline LINGUAGEM & \\
\hline QUAIS & \\
\hline QUATRO & \\
\hline AULAS & \\
\hline ENSINO & \\
\hline CORRIQUEIRO & \\
\hline SINO & \\
\hline
\end{tabular}

f) Si comparamos las palabras (del ejercicio anterior) en portugués y en español, ¿a cuáles conclusiones podemos llegar sobre la relación entre los dos idiomas? ¿Y sobre características especificas del español?

Fonte: as autoras (2021).

A lista, composta por 20 palavras, vai desde um cognato, até um falso cognato, passando por diferentes graus de transparência e opacidade. As duas primeiras palavras (institutos e específicos) são idênticas em espanhol e em português, tanto na forma quanto no significado. As quatro palavras seguintes (metodologia, terminologia, princípios e praticamente) se escrevem da mesma maneira ${ }^{7}$, mas recebem acentuação

\footnotetext{
${ }^{7}$ A última palavra tem uma ortografia um pouco diferente em espanhol, prácticamente. Porém a presença do "c" não influencia em sua transparência, por isso ela está sendo considerada como "igual" ao português (apenas a diferença na acentuação é ressaltada). 
gráfica diferente ${ }^{8}$. A diferença das palavras subsequentes ("prometem" e "utilizam") está na grafia final com -m em português e -n em espanhol. Já em "publicidade", "realidade", "comunicação" e "formulação", a alteração se dá na grafia dos sufixos -dade/-dad e -ção/-ción.

Os pares abordagem/abordaje e linguagem/lenguaje, além da diferença gráfica do sufixo (-agem/-aje) também são heterogenéricos: são femininas em português e masculinas em espanhol. As duas palavras seguintes, quatro e quais, começam em português com a sequência qua-, inexistente em espanhol e, portanto, substituídas, com o mesmo sentido, por cua-. Além disso, o par quais/cuales ainda demonstra uma diferença na constituição do plural de palavras terminadas em -1. Essas 16 primeiras palavras apresentam um grau de transparência elevado e podem ser compreendidas facilmente por falantes de português ao lerem um texto em espanhol e vice-versa, fato que corrobora a eficácia da intercompreensão, já que são $80 \%$ das 20 palavras selecionadas. É importante relembrar que se trata de uma leitura silenciosa: as questões de pronúncia não foram consideradas nesse primeiro momento.

Já as quatro últimas palavras, mais opacas, podem gerar dúvidas nos estudantes. A primeira dupla, ensino/enseñanza, é formada por palavras que têm a mesma origem latina, insignāre (que significa "assinalar") e, por isso, apresentam radicais bastante semelhantes: ensin- e enseñ-, o que facilita um pouco no momento de supor o significado, mesmo se tratando de palavras aparentemente muito distintas. Algo equivalente acontece com a dupla seguinte, corriqueiro/corriente, ambas derivações de "correr" (do latim currens). Porém, nesse caso, a palavra "corriente" pode ser compreendida de maneira equivocada, pois o cognato em português, "corrente", pode sim ser um cognato verdadeiro — quando usado no sentido de "corriqueiro" ou de movimento (de massas de ar, de água, de eletricidade etc.) - , mas também pode ser um falso amigo, já que "corrente" pode também significar o objeto corrente - uma cadeia de argolas, geralmente de metal, que se usa para sustentar ou atar fortemente algo - e, nesse sentido, a palavra equivalente em espanhol é "cadena".

O par de palavras seguinte, aulas/clases, também pode levar a um entendimento equivocado, já que em português também existe a palavra "classes" e em espanhol, "aulas". No entanto, embora as palavras façam referência a algo relacionado ao ensino, não todas são cognatos verdadeiros: "classe", em português, pode ser entendida um

\footnotetext{
${ }^{8}$ As palavras em questão são homófonas, ou seja, têm a mesma sílaba tônica nos dois idiomas, mas seguem regras diferentes de acentuação. A questão da sílaba tônica (pronúncia) não foi destacada neste momento por se tratar de uma leitura silenciosa.
} 
sinônimo de "aula", mas, em espanhol, não. O par aula/clase na língua espanhola se refere a coisas distintas — "aula" é a sala onde acontecem as "clases" — ou seja, esse idioma românico manteve o significado da palavra em latim aula, como um espaço físico (naquele momento, não a sala de aula de uma escola, mas sim o pátio da casa, onde os estudantes recebiam suas lições). Também pode ser assinalada a ortografia de "clases" com apenas um “s”, já que em espanhol não existe o dígrafo "ss".

A última palavra foi escolhida deliberadamente para confundir os alunos menos atentos: "sino". O substantivo comum "sino", em português, é equivalente, em espanhol, ao também substantivo comum "campana", e não à conjunção adversativa "sino" (que, neste texto, poderia ser traduzida como "mas sim"). É claro que, pelo contexto, fica fácil descobrir que a palavra "sino" presente no texto não se refere a um objeto, tanto pela estrutura da frase, quanto pelo conteúdo que está sendo abordado, que em nenhum momento faz qualquer referência a campanas ou a assuntos correlatos. Portanto o aluno deveria responder que "sino" (o objeto) não aparece no texto, mesmo desconhecendo a palavra "campana".

Essas atividades foram elaboradas seguindo os pressupostos principais da intercompreensão, principalmente as noções de "paroquialismo", ou seja, o que cada língua tem de opaco, diferente e único, e (principalmente) de "força do intercurso", isto é, as semelhanças e transparências entre esse idioma e outro - principalmente quando ambos são românicos — as quais permitem as trocas entre os falantes e, consequentemente, o sucesso da comunicação.

O resultado dessa experiência foi bastante válido. Durante os exercícios, os alunos se mostraram, em sua maioria, interessados, atentos e participativos, respondendo de maneira correta quando eram solicitados. Na questão (a), todos consideraram que entenderam mais da metade do texto, sendo que "mais de $70 \%$ " foi a resposta da maioria; nas questões (b), (c) e (d) não demonstraram maiores dificuldades de entendimento, e nas questões (e) e (f) - provavelmente as atividades que mais se diferem do que estudantes de línguas estrangeiras estão acostumados - eles levantaram praticamente sozinhos suposições e conclusões. O "praticamente" se deve ao papel do professor, que, numa abordagem didática que utiliza a intercompreensão, deve atuar apenas "de maneira colaborativa”, pois são os próprios aprendizes — em quem a abordagem está centrada -, guiados por "ajudas pontuais" do professor, que desenvolvem suas próprias estratégias reflexivas, de transferência e de aproximação a partir de bagagens e repertórios individuais e coletivos, e que constroem a arquitetura da nova língua (ESCUDÉ; OLMO, 
2019, p. 73-74, 110). E foi o que aconteceu durante as aulas, tanto na turma A, quanto na turma B.

\section{CONSIDERAÇÕES FINAIS}

Pode-se afirmar que o objetivo principal do uso da intercompreensão no início de um curso de Espanhol Básico foi alcançado. Os alunos entenderam, não apenas teoricamente, mas por meio da experiência prática, que possuem "aptidões inatas e intuitivas para o plurilinguismo" (ESCUDÉ; OLMO, 2019, p. 25). Eles se deram conta que o novo é bem mais conhecido (e, portanto, menos difícil e assustador) do que imaginam, pois mesmo que o português e o espanhol apresentem diferenças (cada um com sua lógica e suas especificidades), são dois idiomas que têm a mesma origem latina e se mantiveram muito parecidos; o que permite que o falante de uma das línguas se aproxime de um texto escrito na outra e consiga compreender facilmente seu sentido global.

\section{Ainda algumas palavras, que bem poderiam ser as nossas...}

Os sujeitos se tornam plurilíngues quando utilizam todos os mais variados recursos "de um repertório plural, composto de capacidades e de conhecimentos desequilibrados e parciais, a fim de se inserir linguística e culturalmente em uma pluralidade de situações"" (MOORE; CASTELLOTTI, 2008, p. 18, tradução nossa).

\section{REFERÊNCIAS}

ANTHONY, E. M. Approach, Method and Technique. English Language Teaching, v.17, 1963.

BEACCO, J. C. (org.) De la diversité linguistique à l'éducation plurilingue: Guide pour l'élaboration des politiques linguistiques éducatives en Europe. Division des Politiques linguistiques. Strasbourg: Conseil de l'Europe, 2005.

CANDELIER, M. (coord.). MAREP - Un Marco de Referencia para los Enfoques Plurales de las Lenguas y de las Culturas Strasbourg: Conselho da Europa, 2013.

\footnotetext{
9 No original: "d'un répertoire pluriel, composé de capacités et de connaissances déséquilibrées et partielles, afin de pouvoir s'insérer, linguistiquement et culturellement, dans une pluralité de situations”. 
CAROLA, C. H. Práticas de Intercompreensão entre línguas românicas: desenvolvimento da competência de leitura plurilíngue de estudantes de ensino médio de uma escola técnica (ETEC) de São Paulo. 225 f. Dissertação (Mestrado em Letras) Departamento de Letras Modernas da Faculdade de Filosofia, Letras e Ciências Humanas, Universidade de São Paulo, 2015.

CEA, B. Abordaje comunicativo en la enseñanza de ELE. Espanhol na Rede. Disponível em: https:/espanholnarede.com/profesores/abordaje-comunicativo-ensenanza-ele/. Acesso em: 20 maio 2020.

ESCUDÉ, P.; OLMO, F. C. D. Intercompreensão: a chave para as línguas. 1 ed. São Paulo: Parábola, 2019.

LEFFA, Vilson J. Metodologia do ensino de línguas. In: BOHN, H. I.; VANDRESEN, P. Tópicos em linguística aplicada: $O$ ensino de línguas estrangeiras. Florianópolis: Ed. da UFSC, 1988. p. 211-236. Disponível em: http://www.leffa.pro.br/textos/trabalhos/ Metodologia_ensino_linguas.pdf. Acesso em: 2 fev. 2021.

MOORE, D.; CASTELLOTTI, V. La compétence plurilingue et pluriculturelle. Genèses et évolutions. In: BLANCHET, Ph.; CHARDENET, P. (ed.). Guide pour la recherche en didactique des langues et des cultures. Approches contextualisées. Paris: Editions des archives contemporaines, 2011. p. 241-252.

PALMERINI, M.; FAONE, S. No caminho em direção à intercompreeensão: uma reflexão epistemológica. Revista X, v. 2, p. 120-155, 2014. Disponível em: https://revistas.ufpr.br/ revistax/article/view/40615. Acesso em: 12 jul. 2020.

PORSETTE, I. C. A intercompreensão no ensino de línguas estrangeiras: reflexões sobre a prática em "Leitura plurilíngue na escola", curso oferecido em uma Escola Estadual de Ensino Médio em Vitória (ES). 213 f. Tese (Doutorado em Letras Neolatinas) Programa de Pós Graduação em Letras Neolatinas da Faculdade de Letras, Universidade Federal do Rio de Janeiro, 2019. 


\section{ANEXOS}

\section{ACTIVIDAD I: INTERCOMPRENSIÓN}

\section{Releia a introdução do texto e responda as perguntas:}

«Cursos de español. Metodología comunicativa.» Esto es lo que prometen casi todas las escuelas que enseñan español como lengua extranjera. Pero, realmente, ¿utilizan el abordaje comunicativo en la enseñanza de ELE?

«Comunicativo» es una palabra que suena bien en el mercado de cursos de idiomas; su significado en el lenguaje ordinario indica comunicación, hablar, conversar; suena algo así como lo contrario de «clases aburridas de gramática».

Por eso es que prácticamente todas las escuelas o institutos de idiomas usan en su publicidad frases de impacto que incluyen la palabra «comunicativo».

Pero, en realidad, el concepto de abordaje comunicativo en la enseñanza de ELE no tiene que ver con el sentido corriente de la palabra «comunicativo», sino que se refiere a un tipo de enseñanza con unos principios bien definidos. O sea:

«Abordaje comunicativo» es un concepto técnico del área de ELE - español como lengua extranjera (y también de la enseñanza de otros idiomas).

El Diccionario de Términos Clave de ELE trae el artículo Enfoque Comunicativo, que define el concepto y lo limita a un tipo específico de enseñanza.

El abordaje comunicativo en la enseñanza de ELE implica una determinada concepción de la lengua (como un medio de comunicación), plantea varios principios de cómo se produce el aprendizaje de una segunda lengua o lengua extranjera, y prescribe determinadas actividades para realizar en clase, las cuales simulan las condiciones de la comunicación en la vida real.

Hay mucha investigación detrás de la formulación de los principios que dan base a este abordaje; verás conceptos y expresiones tales como interacción significativa, competencia comunicativa, las cuatro destrezas, tarea posibilitadora, foco en el significado y no en la forma... Es la jerga profesional, la terminología técnica de nuestra área de estudios: aprendizaje y enseñanza de ELE.

a) De 0 a $100 \%$, quanto você considera que entendeu do texto?

b) O que significa a sigla ELE?

Revista X, v. 16, n. 4, p. 1062-1078, 2021. 
c) De acordo com o texto, as afirmações abaixo são verdadeiras ou falsas? Marque V ou F:

\begin{tabular}{|c|c|c|}
\hline I. & & Metodología comunicativa es lo mismo que "clases aburridas de gramática". \\
\hline II. & & La palabra "comunicativo" es muy utilizada en publicidades de cursos de \\
idiomas.
\end{tabular}

d) Assinale em qual grupo de adjetivos abaixo você encaixaria "aburridas":

\begin{tabular}{|c|c|c|}
\hline I. & & Divertidas, entretenidas, placenteras. \\
\hline II. & & Molestas, tediosas, monótonas. \\
\hline III. & & Importantes, vitales, indispensables. \\
\hline
\end{tabular}

e) Procure no texto as seguintes palavras (em espanhol):

\begin{tabular}{|c|c|}
\hline INSTITUTOS & COMUNICAÇÃO \\
\hline ESPECÍFICOS & FORMULAÇÃO \\
\hline METODOLOGIA & ABORDAGEM \\
\hline TERMINOLOGIA & LINGUAGEM \\
\hline PRINCÍPIOS & QUATRO \\
\hline PRATICAMENTE & QUAIS \\
\hline PROMETEM & ENSINO \\
\hline
\end{tabular}




\begin{tabular}{|c|c|}
\hline UTILIZAM & \\
\hline PUBLICIDADE & \\
\hline REALIDADE & \\
\hline
\end{tabular}

\begin{tabular}{|c|l|}
\hline CORRIQUEIRO & \\
\hline AULAS & \\
\hline SINO & \\
\hline
\end{tabular}

f) Si comparamos las palabras (del ejercicio anterior) en portugués y en español, ¿a cuáles conclusiones podemos llegar sobre la relación entre los dos idiomas? ¿Y sobre características especificas del español?

Recebido em: 01 ago. 2020. Aceito em: 07 out. 2020. 